\title{
Health related quality of life and parental perceptions of child vulnerability among parents of a child with juvenile idiopathic arthritis: results from a web-based survey
}

Lotte Haverman $^{1 *}$, Hedy A van Oers ${ }^{1}$, Heleen Maurice-Stam¹', Taco W Kuijpers ${ }^{2}$, Martha A Grootenhuis ${ }^{1}$ and Marion AJ van Rossum ${ }^{3}$

\begin{abstract}
Background: A chronic illness, such as Juvenile Idiopathic Arthritis (JIA), has an impact on the whole family, especially on parents caring for the ill child. Therefore the aim of this study is to evaluate parental Health Related Quality of Life (HRQOL) and parental perceptions of child vulnerability (PPCV) and associated variables in parents of a child with JIA.

Methods: Parents of all JIA patients (0-18 years) in Amsterdam, the Netherlands, were eligible. HRQOL was measured using the TNO-AZL Questionnaire (TAAQOL) and PPCV using the Child Vulnerability Scale (CVS). The HRQOL of parents of a child with JIA was compared to a norm population, and differences between parents of a child with JIA and active arthritis versus parents of a child with JIA without active arthritis were analyzed (ANOVA). For PPCV, parents of a child with JIA were compared to a norm population, including healthy and chronically ill children (Chi ${ }^{2}$, Mann-Whitney $U$ test). Variables associated with PPCV were identified by logistic regression analyses.

Results: 155 parents (87.5\% mothers) completed online questionnaires. JIA parents showed worse HRQOL than parents of healthy children on one out of twelve domains: fine motor HRQOL $(p<.001)$. Parents of children with active arthritis showed worse HRQOL regarding daily activities $(p<.05)$, cognitive functioning $(p<.01)$ and depressive emotions $(p<.05)$ compared to parents of children without active arthritis. Parents of children with JIA perceived their child as more vulnerable than parents of a healthy child $(p<.001)$ and parents of a chronically ill child $(p<.001)$. Parents of children with active arthritis reported higher levels of PPCV $(p<.05)$ than parents of children without active arthritis. A higher degree of functional disability $(p<.01)$ and shorter disease duration $(p<.05)$ were associated with higher levels of PPCV.
\end{abstract}

Conclusion: The HRQOL of JIA parents was comparable to the HRQOL of parents of a healthy child. JIA parents of a child with active arthritis showed worse HRQOL than parents of a child without active arthritis. Parents perceived their child with JIA as vulnerable.

Keywords: Parents, Child vulnerability, Psychosocial factors, Health related quality of life, Juvenile idiopathic arthritis, Caregivers, Pediatrics, Disease activity

\footnotetext{
* Correspondence: I.haverman@amc.nl

${ }^{1}$ Psychosocial Department, Academic Medical Center, Emma Children's A3-241 Hospital, Postbox 22660, Amsterdam 1100 DD, the Netherlands Full list of author information is available at the end of the article
} 


\section{Background}

Juvenile Idiopathic Arthritis (JIA) is arthritis of unknown etiology that starts before the age of sixteen. It is one of the most common rheumatic diseases in childhood and a major cause of childhood disability. Worldwide, 0.07-4.01 per 1000 children are affected [1]. Children suffering from JIA experience functional impairment due to manifestations of the disease in one or more joints, morning stiffness and fatigue [2]. In addition, children with JIA are more functionally disabled and experience more pain than healthy children, especially children with the diagnosis of JIA and active arthritis [1,3]. There is no definite cure for JIA: treatment is aimed at controlling pain and achieving inactive disease by means of medication [1].

A chronic illness has an impact on the whole family, especially on parents caring for the ill child [4]. Parents of a chronically ill child frequently report mood problems, anxiety, physical problems, cognitive problems and a feeling of lack of control over daily events because of their child's illness [5]. They are also more likely to report higher levels of distress and lower levels of Health Related Quality of Life (HRQOL) than parents of healthy children [6,7]. Parenting a child with a chronic illness affects the roles of parents, such as being a partner, employee or family member [8-11] ultimately resulting in increased burden for parents [12-14]. Moreover, high levels of distress in parents are associated with the child's maladjustment to the illness [15-18].

Like other chronic illnesses, caring for a child with JIA may have many adverse social and emotional consequences for the entire family [19]. It is plausible that parents of a child with JIA do experience psychosocial problems or a worse HRQOL [20]. The psychosocial impact of JIA on parents has been documented only to a limited extend. Some results suggest that mothers of a child with JIA experience increased feelings of depression [21,22], show increased number of mental health problems [23] and increased psychological distress [24]. However, other studies do not find any differences between parents of a child with JIA and comparison groups on parental distress [25], nor on HRQOL, anxiety and depression [26]. In addition, it remains unclear what the influence is of disease activity, functional ability or pain of children with JIA on parental functioning or HRQOL $[19,20,23,24,26]$. Because little is known about these parents, it is important to gain more insight in the parental psychosocial functioning. The parent's well-being affects the well-being of the child [27].

Furthermore, a parent's belief that a child is vulnerable can potentially influence their child's development [28]. Children with a chronic illness tend to be more socially anxious when their parents perceive them as more vulnerable [29]. In addition, high perceived vulnerability can lead to overprotective behavior in parents, to more parental stress, and to psychological problems in children, such as psychosomatic complaints and school underachievement [30,31]. Parents who believe that their child is vulnerable to illness were more likely to keep their children home from school [32]. In addition, increased disease severity and lower parental educational level were associated with higher Parental perceptions of Child vulnerability (PPCV) [29].

The aims of this study are (1) to evaluate the HRQOL measured with the TNO-AZL Questionnaire for Adult's Health Related Quality of Life (TAAQOL) of parents of a child with JIA compared to a Dutch TAAQOL norm group and (2) to compare parents of children with the diagnosis JIA with and without active arthritis on HRQOL, (3) to evaluate the PPCV measured with the Child Vulnerability Scale (CVS) among parents of a child with JIA compared to the Dutch CVS norm group existing of parents with a healthy child and parents with a child with another chronic health condition, (4) to compare parents of children with the diagnosis JIA with and without active arthritis on PPCV, and (5) to identify which parental and child variables are associated with PPCV.

\section{Methods}

Participants

In this study, we collected data from parents of a child (one parent per child) who consulted a pediatric rheumatologist between February 2009 and March 2010 at one of the four referral centers in Amsterdam: the Emma Children's Hospital/AMC, VU Medical Centre, Reade (location Jan van Breemenstraat) and Sint Lucas Andreas Hospital. Parents of a child (aged 0-18 years) with JIA were eligible. Before a planned outpatient consultation, a letter was sent to the parents and patients, which set out the purpose and the procedure of the study. All parents gave informed consent according regulations and the study was approved by the Medical Ethics Committees of the participating centers. A username and password were sent by e-mail to the participating patients enabling them to $\log$ in to the study website providing the online questionnaires. Eligible parents of JIA patients attending the outpatient clinic during the study period who did not complete the questionnaires, were defined as nonparticipants.

\section{Measures}

The following concepts were measured; socio-demographics, medical data, functional ability, Health Related Quality of Life and parental perceptions of child vulnerability.

\section{Socio-demographics and medical data Socio-demographics}

Socio-demographics on participating children and parents were collected using online baseline questionnaires completed by the mother or father. The following 
information concerning the child was obtained: age, age at onset of disease and gender. Children completed a questionnaire about their subjective burden of medication use. Data were obtained from the parents on their age, gender, country of birth, education (low: no education, primary school or primary vocational education; middle: secondary school or secondary vocational education; high: higher vocational education or university), number of children and marital status. Socio-demographic information on the non-participating parents was missing, except the country of birth, because this was registered in the medical files.

\section{Medical data}

The medical data of the participating children were assessed by the pediatrician during the consultation. The medical data of the non-participating children were collected retrospectively, based on the information in the medical files. All patients were classified (JIA type) according to the International League of Associations for Rheumatology (ILAR) criteria [33]. During the consultation, the physician assessed the disease activity on a $100 \mathrm{~mm}$ Visual Analogue Scale (VAS) ( 0 = no disease activity; $100=$ very severe activity) and the number of active joints. These were classified as follows: no active joints (no active arthritis), monoarthritis (1 joint), oligoarthritis ( 2 to 4 joints), polyarthritis (5 to 10 joints), and severe polyarthritis (11 or more active joints). The last four categories were regarded as 'children with active arthritis'. The patient's medication at the time of the consultation was recorded. Current or previous presence of uveitis was noted. The time between disease onset and diagnosis was calculated as well as disease duration (time from disease onset to the date of the consultation).

\section{Functional ability and discomfort CHAQ}

The Dutch version of the Childhood Health Assessment Questionnaire (CHAQ) [34] was used to measure functional ability [35]. The disability index is a summarized score ranging from 0 to 3 , with higher scores indicating higher disability. The CHAQ can be used as a self-report as well as a parent proxy report. In this study, both versions were used: the proxy report (ages 0 to 7 years) and the self-report (ages 8 to 18 years).

\section{Discomfort}

Discomfort was assessed by a $100 \mathrm{~mm}$ VAS for the evaluation of pain $(0=$ no pain; $100=$ very severe pain $)$ and a $100 \mathrm{~mm}$ VAS for the evaluation of overall well-being $(0=$ very well; $100=$ very poor), completed by the parent (ages 0 to 7 years) or patient (ages 8 to 18 years).

\section{Health Related Quality of Life with the TAAQOL}

Parental HRQOL was assessed by the TNO-AZL Questionnaire for Adult's Health Related Quality of Life
(TAAQOL) [36]. The questionnaire was completed by parents. This questionnaire measures health status problems weighted by the impact of problems on well-being on 12 multi-item scales, with higher scores indicating better HRQOL. Each item consists of 2 parts: the first part assesses the prevalence of a health problem or limitation in the past month, and the second part evaluates the emotional response to the health problem or limitation. Answers were scored on 4-point scales. A single score is attributed to each combination of an item assessing the prevalence of a problem or limitation and the corresponding emotional response. The psychometric properties, validity, and reliability of the TAAQOL were satisfactory [36]. The Cronbach's $\alpha$ values in the present study sample were good, ranging from .71 to .92. The norm group consists of parents of healthy children from two Dutch elementary schools and one high school, located in Amsterdam [7].

\section{Parental perceptions of child vulnerability with the CVS}

Perceptions of child vulnerability by mother or father were assessed using the Child Vulnerability Scale (CVS) [28]. The questionnaire was completed by parents. The CVS was translated into Dutch [37]. The CVS consists of eight items with a 4-point response scale ranging from 'definitely false' to 'definitely true' scored from 0 to 3 , with a total score of 0 to 24 . A score equal to or greater than 10 is the cut-off for high vulnerability (defined as scores in the clinical range) [28]. The internal consistency of the Dutch scale was good, with a Cronbach's $\alpha$ value of .70 [37]. The norm group consists of 520 parents of children from 9 Dutch schools. The presence of a chronic health condition was proxy reported. This group $(n=69)$ included: asthma (36.2\%), congenital defect (13.0\%), skin disease (5.8\%) and migraine (5.8\%) [37]. The Cronbach's $\alpha$ in the present study sample was .83 .

\section{Statistical analyses}

The Statistical Package for the Social Sciences (SPSS) version 19.0 was used to manage and analyze the data. First, differences between participants and non-participants were analyzed, using independent samples t-test, MannWhitney U test or $\mathrm{Chi}^{2}$ test.

Second, the TAAQOL scores (HRQOL) were computed according to the manual. HRQOL differences between (1) the parents of a child with JIA and the Dutch norm group, as well as between (2) parents of a child with the diagnosis of JIA without active arthritis (no arthritis) and parents of a child with the diagnosis of JIA with active arthritis (monoarthritis, oligoarthritis, polyarthritis or severe polyarthritis) were analyzed with analysis of variance (ANOVA), corrected for the differences between the groups on sociodemographics, using independent samples t-test, MannWhitney $\mathrm{U}$ test or $\mathrm{Chi}^{2}$ test to analyze the differences. 
Third, the CVS (parental perceptions of child vulnerability, PPCV) total score was computed according to the manual and the answers on the individual CVS items were dichotomized $(0=$ definitely true and mostly true, $1=$ definitely false and mostly false). Differences on the PPCV between the parents of a child with JIA and both norm groups (healthy and chronically ill) were analyzed with Mann Whitney $\mathrm{U}$ tests for the total score and $\mathrm{Chi}^{2}$ tests for the scores in the clinical range (scores $\geq 10$ ) and on the dichotomized item level. The tests mentioned above are also used to study differences in parents of children with JIA with and without active arthritis. It was not necessary to correct the CVS analyses for parental educational level because this characteristic appeared nor to be correlated with the CVS scores in the norm group [37] neither in the parents of children with JIA (correlations .003-.097). Ethnicity was correlated with CVS in the norm group [37] but the groups to be analyzed in the present study did not differ on this characteristic.

Finally, logistic regression analyses were performed to examine which parental and child variables were associated with PPCV, expressed by a score equal or above the cut-off score of 10. First, univariate logistic regression analyses were performed on possible predictive variables. All variables that showed significant $(\mathrm{p}<.05)$ associations with PPCV in the univariate logistic regression analyses were included in the final logistic regression model of PPCV simultaneously, i.e. parental age, number of active joints, disease duration, functional ability (CHAQ total score) and patient and parent reported pain (VAS scores). Parental gender, parental country of birth, parental education, child's age, child's gender, diagnosis, medication use, subjective burden of medication use were therefore excluded. Owing to multicollinearity (high correlation between predictors, correlation > .80), general well-being (VAS score) and physician disease activity score (VAS score) were also excluded.

\section{Results}

\section{Socio-demographic and medical information}

237 parents of children with JIA were approached to participate. Parents and children (above the age of 12) had to give their permission to participate. 168 (61.5\%) of these parents completed the online HRQOL questionnaire and CVS questionnaire. The main reason for parents and children, especially adolescents, not to participate was because they did not feel like they wanted to participate, or because of a lack of time.

A total of 155 parents completed the socio-demographic questionnaire; $87.5 \%$ of the parents were mothers and the mean age was $41.99(\mathrm{SD}=5.40)$. In $83.7 \%$, the parental country of birth was the Netherlands. The distribution of parental educational level was as follows: $13.1 \%$ low, $51.2 \%$ middle, $35.7 \%$ high. $67.3 \%$ of the participating children were female, and the mean age of all children was 11.48 years $(\mathrm{SD}=4.6)($ Table 1$)$.

\section{Functional ability and discomfort}

The CHAQ scores were available from 158 patients. The mean total score was 0.73 (SD 0.8). The mean patient and parent reported VAS pain score and general well-being was respectively 28.67 (SD 29.6) and 27.58 (SD 26.9).

Differences between children without active arthritis and with active arthritis were found on all three outcomes (Mann-Whitney U test); CHAQ mean total score (0.54, SD 0.6 vs 0.97, SD 0.7, $\mathrm{p}<.001)$, VAS pain score (17.6, SD 25.4 vs 38.2 , SD 29.8, $\mathrm{p}<.001)$ and VAS score of general well-being (18.0, SD 23.7 vs 35.8, SD 26.9, p <.001).

\section{HRQOL}

Parents of a child with JIA compared with the Dutch norm Parents of a child with JIA differed from the Dutch norm on the following characteristics: parents of a child with JIA were on average younger (42.0 years, SD 5.4 vs 43.7 years, SD 5.5, $\mathrm{p}<.001)$, were more often married/ living together $(87.5 \%$ vs $83.1 \%, \mathrm{p}<.001)$ and the distribution of parental educational level differed as well $(\mathrm{p}<.05)$. The HRQOL of parents of children with JIA, corrected for parental age and educational level, was comparable to the HRQOL of parents of healthy children on ten of the twelve subscales. Parents of children with JIA scored significantly worse $(\mathrm{p}<.05)$ on the subscale 'fine motor functioning' and significantly better $(\mathrm{p}<.05)$ on the subscale 'social functioning' (Table 2 ).

\section{Parents of a child with JIA without active arthritis compared with parents of a child with JIA with active arthritis}

Parental educational level differed between parents of children with versus without active arthritis $(\mathrm{p}<.05)$. Corrected for their educational level, parents of children with active arthritis showed significantly $(\mathrm{p}<.01)$ worse HRQOL than parents of children without arthritis on the following subscales: daily activities, cognitive functioning and depressive emotions (Table 3).

\section{Parental perceptions of child vulnerability \\ Parents of a child with JIA compared with the Dutch norm}

Parents of a child with JIA perceived their child as more vulnerable compared with parents of a healthy child. Significant differences $(\mathrm{p}<.001)$ were found on the total CVS score, on all items of the CVS, and on the percentages of parents with scores above the cut-off (scores $\geq 10$ ); $31 \%$ of parents of a child with JIA vs $1 \%$ of parents of a healthy child.

Compared with parents of a chronically ill child, parents of a child with JIA also perceived their child as significantly $(\mathrm{p}<.001)$ more vulnerable as expressed 
Table 1 Socio-demographics and disease characteristics of participants and non-participants

\begin{tabular}{|c|c|c|c|c|c|c|c|}
\hline \multirow[b]{2}{*}{ PARENTS } & \multicolumn{3}{|c|}{ Participants } & \multicolumn{3}{|c|}{ Non-participants } & \\
\hline & $\mathbf{N}$ & M & SD & $\mathbf{N}$ & $M$ & SD & \\
\hline \multirow[t]{2}{*}{ Age (years) } & 155 & 41.99 & 5.40 & & & & \\
\hline & $\mathbf{N}$ & $\%$ & & $\mathbf{N}$ & $\%$ & & $\mathbf{p}$ \\
\hline Country of birth parents (Netherlands) & 139 & 83.7 & & 65 & 61.9 & & $<.001^{\mathrm{b}}$ \\
\hline Gender (female) & 147 & 87.5 & & & & & \\
\hline Married/living together & 158 & 94.0 & & & & & \\
\hline \multicolumn{8}{|l|}{ Education } \\
\hline Low & 22 & 13.1 & & & & & \\
\hline Middle & 86 & 51.2 & & & & & \\
\hline High & 60 & 35.7 & & & & & \\
\hline \multicolumn{8}{|l|}{ Number of children } \\
\hline 1 & 22 & 13.1 & & & & & \\
\hline $2-3$ & 135 & 80.3 & & & & & \\
\hline$>3$ & 11 & 6.6 & & & & & \\
\hline CHILDREN & $\mathrm{N}$ & M & SD & $\mathrm{N}$ & M & SD & $\mathrm{p}$ \\
\hline Age (years) & 168 & 11.48 & 4.56 & 105 & 13.28 & 3.87 & $<.001^{\mathrm{a}}$ \\
\hline Age of disease onset & 165 & 7.40 & 4.42 & 104 & 8.61 & 4.46 & $.03^{\mathrm{a}}$ \\
\hline \multirow[t]{2}{*}{ Age of diagnosis } & 168 & 8.58 & 4.69 & 103 & 9.72 & 4.52 & $.05^{\mathrm{a}}$ \\
\hline & $\mathbf{N}$ & $\%$ & & $\mathbf{N}$ & $\%$ & & $p$ \\
\hline Gender (female) & 113 & 67.3 & & 65 & 61.9 & & $.34^{\mathrm{b}}$ \\
\hline JIA subtype & $\mathbf{N}$ & $\%$ & & $\mathbf{N}$ & $\%$ & & $p$ \\
\hline Oligo-articular JIA, persistent & 40 & 13.8 & & 19 & 18.1 & & $.26^{\mathrm{b}}$ \\
\hline Oligo-articular JIA, extended & 21 & 12.5 & & 12 & 11.4 & & $.79^{b}$ \\
\hline Poly-articular JIA, RF negative & 66 & 39.4 & & 46 & 43.8 & & $.46^{\mathrm{b}}$ \\
\hline Poly-articular JIA, RF positive & 5 & 3.0 & & 4 & 3.8 & & $.71^{b}$ \\
\hline Systemic JIA & 7 & 4.2 & & 3 & 2.9 & & * \\
\hline Enthesitis related Arthritis & 18 & 10.7 & & 11 & 10.5 & & $.95^{\mathrm{b}}$ \\
\hline Undifferentiated JIA & 9 & 5.3 & & 8 & 7.7 & & $.50^{\mathrm{b}}$ \\
\hline \multirow[t]{2}{*}{ Chronic arthritis with other autoimmune inflammatory disease } & 2 & 1.2 & & 2 & 1.9 & & * \\
\hline & $\mathbf{N}$ & Median (range) & $\mathbf{N}$ & Median (range) & $\mathbf{p}$ & & \\
\hline Time between symptom onset and diagnosis of JIA (months) & 165 & $0.55(0-8.78)$ & 102 & $0.47(0.1-10.26)$ & & & $.19^{c}$ \\
\hline Disease duration (years) & 165 & $3.46(0.28-14.82)$ & 102 & $3.77(0.45-14.13)$ & & & $.15^{\mathrm{c}}$ \\
\hline Physician disease activity (VAS score range $0-100$ ) & 165 & $15.00(0-84)$ & 102 & $17.00(0-94)$ & & & $.85^{\mathrm{c}}$ \\
\hline Number of joints with arthritis & $\mathbf{N}$ & $\%$ & & $\mathbf{N}$ & $\%$ & & $\mathrm{p}$ \\
\hline No arthritis & 76 & 45.2 & & 46 & 43.8 & & $.82^{\mathrm{b}}$ \\
\hline Monoarthritis (1 joint) & 21 & 12.5 & & 18 & 17.1 & & $.29^{b}$ \\
\hline Oligoarthritis (2-4 joints) & 45 & 26.8 & & 22 & 21.0 & & $.28^{\mathrm{b}}$ \\
\hline Polyarthritis (>4 joints) & 23 & 13.7 & & 19 & 18.1 & & $.57^{b}$ \\
\hline Uveitis presenting during disease course & 8 & 4.8 & & 9 & 8.6 & & $.45^{\mathrm{b}}$ \\
\hline Medication at time point of evaluation & $\mathbf{N}$ & $\%$ & & $\mathbf{N}$ & $\%$ & & $\mathrm{p}$ \\
\hline No medication & 13 & 7.7 & & 16 & 15.2 & & $.05^{\mathrm{b}}$ \\
\hline NSAID & 98 & 58.3 & & 47 & 44.8 & & $.029^{\mathrm{b}}$ \\
\hline
\end{tabular}


Table 1 Socio-demographics and disease characteristics of participants and non-participants (Continued)

\begin{tabular}{|c|c|c|c|c|c|}
\hline DMARDS (including methotrexate, sulfasalazine) & 131 & 78.0 & 76 & 72.4 & $.38^{b}$ \\
\hline Anti-TNF & 24 & 14.3 & 1 & 9.5 & * \\
\hline DMARDS and Biological (Anti-TNF) & 21 & 12.5 & 9 & 8.6 & $.31^{b}$ \\
\hline
\end{tabular}

$\mathrm{a}=$ independent samples T-test, $\mathrm{b}=\mathrm{Chi}^{2}, \mathrm{c}=$ Mann-Whitney $\mathrm{U}$ test, ${ }^{*}=$ less than 5 cases in a cell.

Abbrevations: $J A=$ Juvenile Idiopathic Arthritis, VAS = Visual Analogue Scale, NSAID = Non Steroid Anti-Inflammatory Drug, DMARD = Disease Modifying Anti-

Rheumatic Drug: methotrexate, sulfasalazine, Anti-TNF = anti-Tumor Necrosis Factor: etanercept, adalimumab, infliximab.

both the total score, and by the percentage above the cut-off score; $31 \%$ vs $7.2 \%$ ( $<<.001)$. Significant differences were also found on five of the eight items (Table 4).

\section{Parents of a child with JIA without active arthritis compared with parents of a child with JIA with active arthritis}

Significant differences $(\mathrm{p}<.05)$ were found on the total CVS score between parents of children with active arthritis (median 7, range 4-12) and parents of children without active arthritis (median 5, range 2-9). No differences were found on the percentages of parents with scores above the cut-off (scores $\geq 10$ ) or on the items of the CVS, except for item 1; "In general, my child seems less healthy than other children" (96.2\% for parents of children with active arthritis vs $30.8 \%$ for parents of children without active arthritis, $\mathrm{p}<.05)$.

\section{Identifying variables associated with parental perceptions of child vulnerability}

The results of the final logistic regression analysis are shown in Table 5. The CHAQ total score (functional ability) and disease duration were significantly associated with PPCV $(\mathrm{p}<.05)$. Parents of a child with higher scores on the CHAQ total score, perceived their child as more vulnerable. Shorter disease duration is associated with a more vulnerable perception of the child. Parental age, number of active joints and pain were not significantly related to PPCV.

\section{Discussion}

This study shows that the HRQOL of parents of a child with JIA was comparable to the HRQOL of parents of healthy children. The only differences we found were that parents of a child with JIA scored worse on 'fine motor functioning' and better on 'social functioning'.

These results are in line with some previous research regarding HRQOL of parents of a child with JIA [26]. The normal levels of HRQOL might be explained by the multidisciplinary therapeutic approach in children with JIA and good education of the parents regarding the course and outcome of the illness [26]. In the Netherlands, treatment is coordinated by regular checks by a pediatric rheumatologist and ophthalmologist. Occupational and physical therapy are integral in the management of JIA to improve mobility and help to manage pain. Psychosocial support for the patient and family by a psychologist and social worker is often organized to improve self-management and coping with the impact of the illness in daily life.

The lowered fine motor functioning could be related to the findings that JIA occurs more often in families with presence of other autoimmune or rheumatic diseases

Table 2 HRQOL of parents of children with JIA compared with Dutch norm data

\begin{tabular}{|c|c|c|c|c|c|c|c|}
\hline \multirow[b]{2}{*}{ HRQOL } & \multicolumn{3}{|c|}{ JIA parents $(n=167)$} & \multicolumn{3}{|c|}{ Norm group $(n=425)$} & \multirow[b]{2}{*}{$p$} \\
\hline & $n$ & Mean & SD & $n$ & Mean & SD & \\
\hline Daily activities & 167 & 83.53 & 24.95 & 420 & 85.26 & 21.37 & $.44^{a}$ \\
\hline Aggressive emotions & 167 & 88.82 & 18.64 & 421 & 87.57 & 16.41 & $.17^{\mathrm{a}}$ \\
\hline Cognitive functioning & 167 & 79.90 & 26.30 & 421 & 78.74 & 24.69 & $.32^{\mathrm{a}}$ \\
\hline Fine motoric functioning & 167 & 92.37 & 19.63 & 422 & 96.82 & 9.14 & $<.001^{\mathrm{a}}$ \\
\hline Gross motoric functioning & 167 & 84.96 & 23.04 & 423 & 87.95 & 20.84 & $.30^{\mathrm{a}}$ \\
\hline Pain & 167 & 68.08 & 26.90 & 424 & 72.07 & 22.32 & $.16^{\mathrm{a}}$ \\
\hline Positive emotions & 167 & 67.96 & 21.99 & 422 & 66.57 & 19.93 & $.30^{\mathrm{a}}$ \\
\hline Sexuality & 167 & 87.28 & 23.14 & 405 & 84.72 & 23.58 & $.25^{\mathrm{a}}$ \\
\hline Sleep & 167 & 67.44 & 27.50 & 423 & 70.81 & 25.38 & $.19^{\mathrm{a}}$ \\
\hline Social functioning & 167 & 89.78 & 14.00 & 421 & 83.59 & 20.07 & $.001^{\mathrm{a}}$ \\
\hline Depressive emotions & 167 & 75.45 & 22.34 & 423 & 78.55 & 19.52 & $.18^{\mathrm{a}}$ \\
\hline Vitality & 167 & 60.53 & 24.62 & 423 & 63.36 & 22.63 & $.39^{\mathrm{a}}$ \\
\hline
\end{tabular}

$\mathrm{a}=$ Analysis of variance, with parental age and educational level as covariates. 
Table 3 HRQOL of parents of children with JIA without active arthritis in comparison to parents of children with JIA with active arthritis

\begin{tabular}{|c|c|c|c|c|c|c|c|}
\hline \multirow[b]{2}{*}{ HRQOL } & \multicolumn{3}{|c|}{ No arthritis $(n=76)$} & \multicolumn{3}{|c|}{ Arthritis $(n=92)$} & \multirow[b]{2}{*}{$\mathrm{p}$} \\
\hline & $\mathbf{n}$ & Mean & SD & $\mathbf{n}$ & Mean & SD & \\
\hline Daily activities & 76 & 88.57 & 19.75 & 91 & 79.33 & 27.99 & $.03^{\mathrm{a}}$ \\
\hline Aggressive emotions & 76 & 89.33 & 15.55 & 91 & 88.40 & 20.95 & $.69^{a}$ \\
\hline Cognitive functioning & 76 & 87.75 & 20.09 & 91 & 73.35 & 29.06 & $.001^{\mathrm{a}}$ \\
\hline Fine motoric functioning & 76 & 94.90 & 15.30 & 91 & 90.25 & 22.48 & $.19^{\mathrm{a}}$ \\
\hline Gross motoric functioning & 76 & 87.58 & 19.62 & 91 & 82.76 & 25.45 & $.33^{\mathrm{a}}$ \\
\hline Pain & 76 & 69.90 & 26.55 & 91 & 66.55 & 27.23 & $.65^{\mathrm{a}}$ \\
\hline Positive emotions & 76 & 70.29 & 22.95 & 91 & 66.03 & 21.09 & $.23^{\mathrm{a}}$ \\
\hline Sexuality & 76 & 87.01 & 23.93 & 91 & 87.50 & 22.59 & $.91^{\mathrm{a}}$ \\
\hline Sleep & 76 & 71.71 & 26.23 & 91 & 63.87 & 28.16 & $.08^{\mathrm{a}}$ \\
\hline Social functioning & 76 & 91.28 & 13.70 & 91 & 88.53 & 14.20 & $.27^{\mathrm{a}}$ \\
\hline Depressive emotions & 76 & 80.26 & 20.22 & 91 & 71.43 & 23.31 & $.02^{\mathrm{a}}$ \\
\hline Vitality & 76 & 64.58 & 22.78 & 91 & 57.14 & 25.69 & $.11^{\mathrm{a}}$ \\
\hline
\end{tabular}

$\mathrm{a}=$ Analysis of variance, with educational level as covariate.

$[38,39]$. It was not possible to control for this aspect, because data about the presence of a parental chronic illness were not available.

Earlier, we studied the HRQOL of the children with JIA from the parents in the present study [40]. The children reported a worse HRQOL compared with their peers. It is remarkable that the HRQOL of parents is not affected while the children reported very poor HRQOL, because it is known that children's well-being and parents' HRQOL and psychosocial functioning are associated. When children are chronically ill, parents are often more distressed and more at risk for a lower HRQOL compared to parents of healthy children $[7,41]$. Moreover, high levels of distress in parents are associated with the child's maladjustment to the illness [15-18].

It is questionable whether a generic HRQOL measurement such as the TAAQOL which was used in our study, is sensitive enough to measure HRQOL in parents of a chronically ill child or that specific measurements for parents of a chronically ill child would detect HRQOL

Table 4 Results on the Child Vulnerability Scale (CVS) in parents of children with JIA, compared with a reference group of Dutch parents of both healthy and chronically ill children

\begin{tabular}{|c|c|c|c|c|c|c|c|c|}
\hline \multirow[b]{2}{*}{ CVS } & \multicolumn{2}{|c|}{$\begin{array}{c}\text { JIA parents } \\
(\mathrm{N}=168)\end{array}$} & \multicolumn{3}{|c|}{$\begin{array}{l}\text { Reference group } \\
\text { healthy child } \\
(\mathrm{N}=450)\end{array}$} & \multicolumn{3}{|c|}{$\begin{array}{l}\text { Reference group } \\
\text { chronically ill child } \\
(\mathrm{N}=69)\end{array}$} \\
\hline & \multicolumn{2}{|c|}{$\begin{array}{c}\text { Median } \\
(25-75 \%)\end{array}$} & \multicolumn{2}{|c|}{$\begin{array}{c}\text { Median } \\
(25-75 \%)\end{array}$} & $p$ & \multicolumn{2}{|c|}{$\begin{array}{c}\text { Median } \\
(25-75 \%)\end{array}$} & $p$ \\
\hline \multirow[t]{2}{*}{ Total score CVS - range 0-24 } & \multicolumn{2}{|c|}{$6(3-11)$} & \multicolumn{2}{|c|}{$1(0-3)$} & \multirow{2}{*}{$\begin{array}{l}<.001^{b} \\
\mathbf{p}\end{array}$} & \multicolumn{2}{|c|}{$4(1-6)$} & $<.001^{b}$ \\
\hline & $\mathbf{N}$ & $\%$ & $\mathbf{N}$ & $\%$ & & $\mathbf{N}$ & $\%$ & $\mathbf{p}$ \\
\hline Above cut-off score & 52 & 31.0 & 5 & 1.1 & $<.001^{\mathrm{a}}$ & 5 & 7.2 & $<.001^{\mathrm{a}}$ \\
\hline Items, (mostly) true: & $\mathbf{N}$ & $\%$ & $\mathbf{N}$ & $\%$ & $\mathbf{p}$ & $\mathbf{N}$ & $\%$ & $\mathbf{p}$ \\
\hline 1. In general, my child seems less healthy than other children. & 52 & 31.0 & 9 & 2.0 & $<.001^{\mathrm{a}}$ & 6 & 8.7 & $<.001^{\mathrm{a}}$ \\
\hline 2. I often think about calling the doctor about my child. & 22 & 13.1 & 4 & 0.9 & $<.001^{\mathrm{a}}$ & 6 & 8.7 & $.340^{\mathrm{a}}$ \\
\hline 3. When there is something going around my child usually catches it. & 50 & 29.8 & 26 & 5.8 & $<.001^{\mathrm{a}}$ & 9 & 13.0 & $.008^{a}$ \\
\hline 4. I often check on my child at night to make sure that s/he is okay. & 40 & 23.8 & 37 & 8.2 & $<.001^{\mathrm{a}}$ & 13 & 18.8 & $.404^{a}$ \\
\hline 5. Sometimes I get concerned that my child doesn't look as healthy as s/he should. & 55 & 32.7 & 15 & 3.3 & $<.001^{\mathrm{a}}$ & 9 & 13.0 & $.002^{a}$ \\
\hline 6. I often have to keep my child indoors because of health reasons. & 16 & 9.5 & 1 & 0.2 & $<.001^{\mathrm{a}}$ & 6 & 8.7 & $.842^{\mathrm{a}}$ \\
\hline 7. I get concerned about circles under my child's eyes. & 40 & 23.8 & 13 & 2.9 & $<.001^{\mathrm{a}}$ & 8 & 11.6 & $.034^{\mathrm{a}}$ \\
\hline 8. My child gets more colds than other children I know. & 50 & 29.8 & 17 & 3.8 & $<.001^{\mathrm{a}}$ & 10 & 14.5 & $.014^{\mathrm{a}}$ \\
\hline
\end{tabular}

$\mathrm{a}=\mathrm{Chi}^{2}, \mathrm{~b}=$ Mann-Whitney $\mathrm{U}$ test.

Higher scores represent more perceived vulnerability of the child.

NOTE: Cut-off point high perceived vulnerability: total score of 10 and above [28]. 
Table 5 Logistic regression model of parental perceptions of child vulnerability predicted by parental and child variables

\begin{tabular}{lccc}
\hline $\mathbf{N}=\mathbf{1 4 5}$ & OR & $\begin{array}{c}\mathbf{9 5 \%} \text { confidence } \\
\text { interval }\end{array}$ & $\mathbf{p}$ \\
\hline Parental age & .96 & {$[.88-1.04]$} & .29 \\
Number of active joints & 1.39 & {$[.96-2.01]$} & .08 \\
Disease duration & .81 & {$[.68-.98]$} & .03 \\
Functional disability (CHAQ total score) & 3.23 & {$[1.39-7.53]$} & $<.01$ \\
Pain (VAS scores) & .99 & {$[.98-1.02]$} & .95 \\
\hline
\end{tabular}

problems better. Future research should focus on the relationship between the HRQOL of children with JIA and the HRQOL of their parents.

On the other hand, parents of a child with JIA with active arthritis showed a worse HRQOL compared with parents of a child with JIA without arthritis; especially on the subscales 'daily activities', 'cognitive functioning,' and 'depressive emotions'. Although results of previous studies are unclear about the relationship between a child's disease severity and parental HRQOL, our findings suggest the influence of an active disease status on the parental HRQOL.

Parents of a child with JIA perceived their child as more vulnerable compared with parents of a healthy child and compared with parents of a child with other chronic health conditions. This is in line with findings in other patient groups [31,42] and in a previous study on parents of a child with JIA [29]. An important question is whether the scores are excessively high or a good reflection of the child's vulnerability, because children with JIA are "truly vulnerable" compared with healthy children. The perceptions of the parents to perceive their children with JIA as more vulnerable than healthy children may be realistic [28], because children with JIA do have a chronic illness and are in some way more vulnerable in having doctors' visits, looking less healthy and staying at home because of health complaints. However, it is known that parents who perceive their chronically ill child as more vulnerable are more likely to overprotect their child [43]. This overprotection may hamper the child to develop the personal skills needed to cope with the challenges of growing up with a chronic disease. Therefore, health care providers should encourage parents to stimulate the independence of their child [44].

Parents of a child with JIA with active arthritis perceived their child overall as more vulnerable compared with parents of a child with JIA without arthritis, as indicated by the total score for perceived vulnerability. In addition, they think more often that their child seems less healthy than other children. These findings suggest an influence of disease activity on parental perceptions of child vulnerability.
To get more insight in the PPCV, we aimed to identify variables associated with the PPCV. Our study shows that parents of a more functionally disabled child report to perceive their child as more vulnerable. When the disease duration is shorter, parents also perceive their child as more vulnerable. It is known that for parents, the first confrontation with the knowledge that their child has a chronic illness is a stressful and potentially traumatic event. After the initial shock of the diagnosis, the impact of the disease and its treatments on the child and family may gradually become more clear and results in less worrying thoughts in parents [45].

The findings of this study are qualified by several limitations, including the analysis performed to identify parental and child variables associated with PPCV. Because of multicollinearity, the VAS general well-being and physician disease activity could not be included in the final logistic regression model of PPCV, while these factors appeared to be correlated with PPCV in the univariate logistic analyses.

Regarding the differences we found on parental perceptions of child vulnerability between JIA parents and parents of children with a chronic illness in the norm population, the following should be taken into account. It is plausible that the more severely ill children were not included in the norm population, since the sample for the norm population was collected from regular schools. Because the identification of children with a chronic health condition was based on parental report, objective information on disease severity was not available.

This study analyzed cross-sectional data, which makes it impossible to draw any conclusions about the causality between the associated parental and child variables with PPCV.

The medical data of the non-participating children were collected retrospectively and the parental country of birth was retrieved from the medical records. Based on this data the participants differed significantly from the non-participants on parental country of birth, child's age and medication. Therefore, it is hard to generalize these results to the whole group parents with a child with JIA. The literature on the psychosocial impact of parents of children with JIA is inconsistent; some studies reported significant psychosocial impact on parents, while others found no differences in parents of a child with JIA compared with normative data. Most studies are retrospective reports, consist of a relatively small sample of children or parents [46] and were published more than a decade ago. Therefore, these data may not be representative for the current group of children with JIA and their parents, since the treatment of children with JIA has significantly improved over recent years [1]. Due to these treatment changes, it is to be expected that more children and adolescents with JIA will have a 
better HRQOL and less overall burden of the disease over time. As a consequence, parents may also experience less psychosocial problems.

Our study contributes to the existing literature on functioning of parents of a child with JIA because of the relatively large study sample and the inclusion of two important outcomes in the parental functioning and care for a chronically ill child; HRQOL and PPCV. A strong point of this study is that we did not only focus on outcomes of parental functioning, but also on the determinants. We used a website for data collection. Using the Internet for participants to complete the questionnaires is valid and reliable and less time-consuming compared to a paper and pencil version, and with less missing data.

\section{Conclusions}

In conclusion, there is a need for further research on the HRQOL, psychosocial functioning, needs and PPCV in parents of a child with JIA to gain knowledge on the starting points for developing interventions for these parents to improve their well-being, and also their child's well-being. A recent review about psychological interventions for parents of children with a chronic illness shows that psychological interventions for parents can help reduce pain in children with painful conditions [46]. It is well-known that pain in children with JIA predicts their HRQOL [40]. Therefore, children's HRQOL could be improved through psychological interventions for their parents. So, while caring for their child is the first priority, parent's potential burden should be recognized, as well as their stress levels and reactions to the uncontrollable aspects of the illness. To improve the care for children with JIA, more attention should be paid to research on the parents.

\section{Key messages}

- The HRQOL of parents of a child with JIA was comparable to the HRQOL of parents of a healthy child.

- Parents of a child with active arthritis showed worse HRQOL than parents of a child without active arthritis.

- Parents perceived their child with JIA as more vulnerable than parents of a healthy child or parents of a child with other chronic health conditions.

- Parents perceived their child as more vulnerable when their child with JIA was more functionally disabled and had a shorter disease duration.

\section{Abbreviations}

ANOVA: Analysis of variance; CVS: Child Vulnerability Scale; CHAQ: Childhood Health Assessment Questionnaire; HRQOL: Health Related Quality of Life; ILAR: International League of Associations for Rheumatology; JA: Juvenile
Idiopathic Arthritis; PPCV: Parental perceptions of child vulnerability; SPSS: Statistical Package for the Social Sciences; TAAQOL: TNO-AZL Questionnaire for Adult's Health Related Quality of Life; VAS: Visual Analogue Scale.

\section{Competing interests}

The authors declare that they have no competing interests. Pfizer BV Pharmaceuticals and AGIS Healthcare had no role in the study design, data collection, data analysis, or writing of this manuscript. Publication of this article was not contingent on the approval of these study sponsors.

\section{Authors' contributions}

LH made substantial contributions to the conception and design of the study and to the interpretation of data, collected the data, performed the analyses, helped to draft the article or to review it critically for important intellectual content, and gave final approval of the version to be published. HvO made substantial contributions to the interpretation of data, performed the analyses, helped to draft the article or to review it critically for important intellectual content, and gave final approval of the version to be published. HMS made substantial contributions to the conception and design of the study and to the interpretation of data, performed the analyses, helped to draft the article or to review it critically for important intellectual content, and gave final approval of the version to be published. TW made substantial contributions to the conception and design of the study and to the interpretation of data, helped to draft the article or to review it critically for important intellectual content, and gave final approval of the version to be published. MG made substantial contributions to the conception and design of the study and to the interpretation of data, helped to draft the article or to review it critically for important intellectual content, and gave final approval of the version to be published. MvR made substantial contributions to the conception and design of the study and to the interpretation of data, helped to draft the article or to review it critically for important intellectual content, and gave final approval of the version to be published. All authors read and approved the final manuscript.

\section{Acknowledgements}

We would like to thank all the parents who participated in this study. In addition, we would like to thank Biomedia/Artsen voor Kinderen for the web design.

\section{Financial disclosure}

The authors have indicated they have no financial relationships relevant to this article to disclose.

The source(s) of support in the form of grants or industrial support This work was supported by Pfizer BV Pharmaceuticals and AGIS Healthcare.

\section{Author details}

${ }^{1}$ Psychosocial Department, Academic Medical Center, Emma Children's A3-241 Hospital, Postbox 22660, Amsterdam 1100 DD, the Netherlands. ${ }^{2}$ Department of Pediatric Hematology, Immunology and Infectious Diseases, Academic Medical Center, Emma Children's Hospital, Amsterdam, the Netherlands. ${ }^{3}$ Department of Pediatric Hematology, Immunology and Infectious Diseases, and Reade (Location Jan van Breemen), Department of Pediatric Rheumatology, Amsterdam, the Netherlands.

Received: 13 April 2014 Accepted: 23 July 2014

Published: 7 August 2014

\section{References}

1. Prince FH, Otten MH, van Suijlekom-Smit LW: Diagnosis and management of juvenile idiopathic arthritis. BMJ 2010, 341:c6434.

2. Moorthy LN, Peterson MG, Harrison MJ, Onel KB, Lehman TJ: Physical function assessment tools in pediatric rheumatology. Pediatr Rheumatol Online J 2008, 6:9.

3. Gowdie PJ, Tse SM: Juvenile idiopathic arthritis. Pediatr Clin North Am 2012, 59:301-327.

4. Kazak AE, Kassam-Adams N, Schneider S, Zelikovsky N, Alderfer MA, Rourke $\mathrm{M}$ : An integrative model of pediatric medical traumatic stress. J Pediatr Psychol 2006, 31:343-355. 
5. Murphy NA, Christian B, Caplin DA, Young PC: The health of caregivers for children with disabilities: caregiver perspectives. Child Care Health Dev 2007, 33:180-187.

6. Wolfe-Christensen C, Mullins LL, Stinnett TA, Carpentier MY, Fedele DA: Use of the Behavioral Assessment System for Children 2nd Edition: Parent Report Scale in pediatric cancer populations. J Clin Psychol Med Settings 2009, 16:322-330.

7. Hatzmann J, Heymans HS, Carbonell A, van Praag BM, Grootenhuis MA Hidden consequences of success in pediatrics: parental health-related quality of life-results from the Care Project. Pediatrics 2008, 122:e1030-e1038.

8. Heaton J, Noyes J, Sloper P, Shah R: Families' experiences of caring for technology-dependent children: a temporal perspective. Health Soc Care Community 2005, 13:441-450

9. Brandon P: Time away from "smelling the roses": where do mothers raising children with disabilities find the time to work? Soc Sci Med 2007, 65:667-679.

10. Kirk S: Families' experiences of caring at home for a technologydependent child: a review of the literature. Child Care Health Dev 1998, 24:101-114.

11. Wilson LS, Moskowitz JT, Acree M, Heyman MB, Harmatz P, Ferrando SJ, Folkman S: The economic burden of home care for children with HIV and other chronic illnesses. Am J Public Health 2005, 95:1445-1452.

12. Heyman MB, Harmatz P, Acree M, Wilson L, Moskowitz JT, Ferrando S, Folkman S: Economic and psychologic costs for maternal caregivers of gastrostomy-dependent children. J Pediatr 2004, 145:511-516.

13. Hatzmann J, Maurice-Stam H, Heymans HS, Grootenhuis MA: A predictive model of Health Related Quality of life of parents of chronically ill children: the importance of care-dependency of their child and their support system. Health Qual Life Outcomes 2009, 7:72.

14. Lindstrom C, Aman J, Norberg AL: Increased prevalence of burnout symptoms in parents of chronically ill children. Acta Paediatr 2010, 99:427-432.

15. Grootenhuis MA, Bronner MB: Paediatric illness! Family matters. Acta Paediatr 2009, 98:940-941.

16. Waxmonsky J, Wood BL, Stern T, Ballow M, Lillis K, Cramer-Benjamin D, Mador J, Miller BD: Association of depressive symptoms and disease activity in children with asthma: methodological and clinical implications. J Am Acad Child Adolesc Psychiatry 2006, 45:945-954.

17. Lim J, Wood BL, Miller BD: Maternal depression and parenting in relation to child internalizing symptoms and asthma disease activity. J Fam Psychol 2008, 22:264-273

18. Lopez WL, Mullins LL, Wolfe-Christensen C, Bourdeau T: The Relation Between Parental Psychological Distress and Adolescent Anxiety in Youth With Chronic Illnesses: The Mediating Effect of Perceived Child Vulnerability. Children's Health Care 2008, 37:171-182

19. Barlow JH, Wright CC, Shaw KL, Luqmani R, Wyness IJ: Maternal stressors, maternal wellbeing and children's wellbeing in the context of juvenile idiopathic arthritis. [References]. Early Child Dev Care 2002, 172:89-98.

20. Wallander JL, Varni JW: Effects of pediatric chronic physical disorders on child and family adjustment. J Child Psychol Psychiatry 1998, 39:29-46.

21. Akikusa JD, Allen RC: Reducing the impact of rheumatic diseases in childhood. Best Pract Res Clin Rheumatol 2002, 16:333-345.

22. Timko C, Stovel KW, Moos RH: Functioning among mothers and fathers of children with juvenile rheumatic disease: a longitudinal study. J Pediatr Psychol 1992, 17:705-724

23. Lustig JL, Ireys HT, Sills EM, Walsh BB: Mental health of mothers of children with juvenile rheumatoid arthritis: appraisal as a mediator. $J$ Pediatr Psychol 1996, 21:719-733.

24. Manuel JC: Risk and resistance factors in the adaptation in mothers of children with juvenile rheumatoid arthritis. J Pediatr Psychol 2001, 26:237-246.

25. Gerhardt CA, Vannatta K, McKellop JM, Zeller M, Taylor J, Passo M, Noll RB: Comparing parental distress, family functioning, and the role of social support for caregivers with and without a child with juvenile rheumatoid arthritis. J Pediatr Psychol 2003, 28:5-15.

26. Press J, Neumann L, Uziel Y, Bolotin A, Buskila D: Assessment of quality of life of parents of children with juvenile chronic arthritis. Clin Rheumatol 2002, 21:280-283.
27. Wagner JL, Chaney JM, Hommel KA, Page MC, Mullins LL, White MM, Jarvis $\mathrm{JN}$ : The influence of parental distress on child depressive symptoms in juvenile rheumatic diseases: the moderating effect of illness intrusiveness. J Pediatr Psychol 2003, 28:453-462

28. Forsyth BW, Horwitz SM, Leventhal JM, Burger J, Leaf PJ: The child vulnerability scale: an instrument to measure parental perceptions of child vulnerability. J Pediatr Psychol 1996, 21:89-101.

29. Anthony KK, Gil KM, Schanberg LE: Brief report: Parental perceptions of child vulnerability in children with chronic illness. J Pediatr Psychol 2003, 28:185-190.

30. Thomasgard M, Metz WP: Parental overprotection and its relation to perceived child vulnerability. Am J Orthopsychiatry 1997, 67:330-335.

31. Vrijmoet-Wiersma CM, Egeler RM, Koopman HM, Bresters D, Norberg AL, Grootenhuis MA: Parental stress and perceived vulnerability at 5 and 10 years after pediatric SCT. Bone Marrow Transplant 2010, 45:1102-1108.

32. Spurrier NJ, Sawyer MG, Staugas R, Martin AJ, Kennedy D, Streiner DL: Association between parental perception of children's vulnerability to illness and management of children's asthma. Pediatr Pulmonol 2000, 29:88-93.

33. Petty RE, Southwood TR, Manners P, Baum J, Glass DN, Goldenberg J, He X, Maldonado-Cocco J, Orozco-Alcala J, Prieur AM, Suarez-Almazor ME, Woo P: International League of Associations for Rheumatology classification of juvenile idiopathic arthritis: second revision, Edmonton, 2001. J Rheumatol 2004, 31:390-392.

34. Singh G, Athreya BH, Fries JF, Goldsmith DP: Measurement of health status in children with juvenile rheumatoid arthritis. Arthritis \& Rheumatism 1994, 37:1761-1769.

35. Wulffraat N, van der Net JJ, Ruperto N, Kamphuis S, Prakken BJ, Ten CR, Van Soesbergen RM, Van Rossum MA, Raat H, Landgraf JM, Kuis W: The Dutch version of the Childhood Health Assessment Questionnaire (CHAQ) and the Child Health Questionnaire (CHQ). Clin Exp Rheumatol 2001, 19:111-115.

36. Bruil J, Fekkes M, Vogels T, Verrips GHW: TAAQOL Manual. Leiden: LUMC TNO: Leiden Center for Child Health and Pediatrics: LUMC-TNO; 2004.

37. Houtzager BA, Moller E, Maurice-Stam H, Last BF, Grootenhuis MA: Parental perceptions of child vulnerability in relation to chronic illness and health related quality of life in a community based sample. J Child Health Care 2014, : [Epub ahead of print].

38. Thompson SD, Moroldo MB, Guyer L, Ryan M, Tombragel EM, Shear ES, Prahalad S, Sudman M, Keddache MA, Brown WM, Giannini EH, Langefeld CD, Rich SS, Nichols WC, Glass DN: A genome-wide scan for juvenile rheumatoid arthritis in affected sibpair families provides evidence of linkage. Arthritis Rheum 2004, 50:2920-2930.

39. Zeft A, Shear ES, Thompson SD, Glass DN, Prahalad S: Familial autoimmunity: maternal parent-of-origin effect in juvenile idiopathic arthritis. Clin Rheumatol 2008, 27:241-244.

40. Haverman L, Grootenhuis MA, van den Berg JM, Van Veenendaal M, Dolman KM, Swart JF, Kuijpers TW, Van Rossum MA: Predictors of health-related quality of life in children and adolescents with juvenile idiopathic arthritis: results from a web-based survey. Arthritis Care Res 2014, 64:694-703.

41. van Oers HA, Haverman L, Limperg PF, van Dijk-Lokkart EM, Maurice-Stam $\mathrm{H}$, Grootenhuis MA: Anxiety and depression in Mothers and Fathers of a chronically ill child. Matern Child Health 2014.

42. Rait DS, Ostroff JS, Smith K, Cella DF, Tan C, Lesko LM: Lives in a balance: perceived family functioning and the psychosocial adjustment of adolescent cancer survivors. Fam Process 1992, 31:383-397.

43. Stam H, Hartman EE, Deurloo JA, Groothoff J, Grootenhuis MA: Young adult patients with a history of pediatric disease: impact on course of life and transition into adulthood. J Adolesc Health 2006, 39:4-13.

44. Weathers FW, Keane TM: The Criterion A problem revisited: controversies and challenges in defining and measuring psychological trauma. J Trauma Stress 2007, 20:107-121.

45. Reisine ST: Arthritis and the family. Arthritis Care Res 1995, 8:265-271.

46. Eccleston C, Palermo TM, Fisher E, Law E: Psychological interventions for parents of children and adolescents with chronic illness. Cochrane Database Syst Rev 2012, 8:CD009660.

\section{doi:10.1186/1546-0096-12-34}

Cite this article as: Haverman et al.: Health related quality of life and parental perceptions of child vulnerability among parents of a child with juvenile idiopathic arthritis: results from a web-based survey. Pediatric Rheumatology 2014 12:34. 